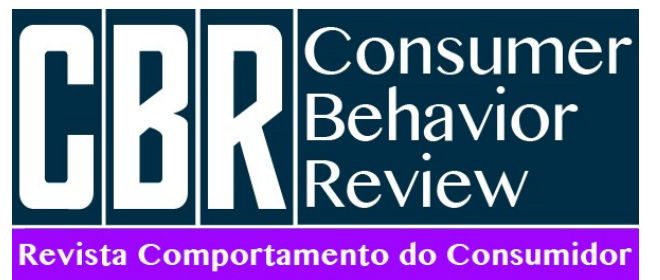

Teodoro, A. J. S., Carvalho, E. G., Silva, M. G., \& Andrade, R. H. R. (2021). Produto e Ponto de Venda: Aspectos que influenciam a frequência de compra de carne. Consumer Behavior Review, 5(3), 356-372.

DOI: https://doi.org/10.51359/2526-7884.2021.251057

ISSN: 2526-7884

Editor: Prof. Dr. Marconi Freitas da Costa

E-mail: cbr@ufpe.br
Avaliação: Double blind review

Recebido: 02 de julho de 2021

Aprovado: 12 de agosto de 2021

\title{
PRODUTO E PONTO DE VENDA: ASPECTOS QUE INFLUENCIAM A FREQUÊNCIA DE COMPRA DE CARNE
}

\author{
Product and Point of Sale: Aspects that influence meat purchase frequency
}

\author{
Alberdan José da Silva Teodoro ${ }^{1}$ \\ ORCID: http://orcid.org/0000-0002-9315-218X \\ E-mail: alberdan.teodoro@estudante.ufla.br \\ Eduardo Gomes Carvalho ${ }^{2}$ \\ ORCID: http://orcid.org/0000-0002-5266-375X \\ E-mail: eduardogomes@cefetmg.br \\ Marcos Giovane da Silva ${ }^{1}$ \\ ORCID: http://orcid.org/0000-0001-8410-6053 \\ E-mail: marcosufsj21@gmail.com \\ Rondinelli Heitor Resende Andrade ${ }^{1}$ \\ ORCID: http://orcid.org/0000-0003-2585-817X \\ E-mail: rondinelliandrade@hotmail.com \\ ${ }^{1}$ Universidade Federal de Lavras, Lavras, Brasil \\ ${ }^{2}$ Centro Federal de Educação Tecnológica de Minas Gerais, Varginha, Brasil
}

\begin{abstract}
Resumo
Objetivo: 0 presente estudo tem como objetivo propor um modelo capaz de identificar quais aspectos relacionados à carne e ao ponto de venda influenciam a frequência de compra dos
\end{abstract}

\begin{abstract}
Objective: This study aims to propose a model capable of identifying which aspects related to meat and the point of sale influence the frequency of purchase of meat fans.
\end{abstract}


adeptos de carne.

Método: Desenvolveu-se um estudo de caso único, quantitativo, exploratório, tipo survey em uma casa de carnes em uma cidade do sul de Minas Gerais. Para a execução utilizou-se do

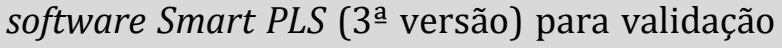
do modelo de mensuração reflexivo e estrutural proposto.

Resultados: As características intrínsecas da carne influenciam as características extrínsecas e os benefícios experienciais sobre o produto. Além disso, o bom relacionamento do consumidor com o gestor e os funcionários influenciam positivamente a frequência de compra.

Originalidade/relevância: 0 estudo identificou aspectos relacionados ao produto e ao ponto de venda capazes de influenciar o comportamento dos consumidores de carne quanto a frequência de compra do produto.

Palavras-chave: Consumo de carne; Smart PLS; Modelo reflexivos.
Method: A single, quantitative, exploratory, survey-type study was developed in a meat house in a city in the south of Minas Gerais. For the execution, the Smart PLS software, 3 rd version, was used to validate the reflexive and structural measurement model proposed. Results: The intrinsic characteristics of the meat influence both the extrinsic characteristics and the experiential benefits on the product. In addition, the good relationship between the consumer through the manager and employee positively influences the purchase frequency.

Originality/relevance: The study identified aspects related to the product and the organization capable of influencing the behavior of meat consumers regarding product adherence.

Keywords: Meat consumption; Smart PLS; Reflective model.

This work is licensed under a Creative Commons Attribution 4.0 International License.

\section{INTRODUÇÃO}

Estudiosos, desde 1900 compreenderam que ao avaliar a percepção dos consumidores sobre a qualidade da carne, devem se preocupar em entender e atender as necessidades dos consumidores e sua aceitação pelo produto. Em 1990, estudos já mostravam uma tendência dos consumidores em avaliar a maciez da carne sobre a noção de gosto, mas na atualidade o sabor tornou-se o mais visado (Miller, 2020). O comportamento de consumo inclui os pensamentos, sentimentos e atitudes envolvendo a seleção, compra e consumo de produtos ou serviços (Marin, 2015).

As decisões dos consumidores podem ser categorizadas em algumas tipologias, sendo elas: 'decisões estendidas' - aquelas que exigem um tempo maior de pesquisa e existência de alto risco, ocasionado pela complexidade do produto sobre a experiência do consumidor; 'decisões limitadas' quando ocorre a existência moderada de riscos, sendo que os consumidores estão dispostos a perder um pouco de tempo durante sua atividade de compra; 'decisões rotineiras' - referentes a existência mínima de riscos. Em suma, o consumidor evita perder tempo e, assim, despender menos esforços. Além disso, tais decisões podem ser programadas, as quais existe e/ou exige um planejamento de compra, ou não programadas, em que é caracterizada pela pouca ou nenhuma forma de planejamento para compra (Marin, 2015). Estudos seguem sendo realizados sobre o consumo de carne no Brasil e no mundo (O'Reilly et al., 2020; Cipriano et al., 2021, Dudinskaya et al., 2021; Frank et al., 2021), o que significa dizer que, apesar das inúmeras investigações realizadas, a temática ainda não é exaustiva.

Na China, a disponibilidade de informações demonstrou-se eficaz para a mudança de atitude, aceitação e disposição dos consumidores sobre a carne (Zhang, Li, \& Bai, 2020). Por sua vez, nos Estados Unidos, as características demográficas dos consumidores podem influenciar o consumo de carne. Os consumidores mais jovens, bem como os de baixa renda valorizam a suculência da carne, enquanto os mais velhos e as pessoas de maior renda, a maciez. No que tange as características sensoriais obtidas pelo consumo de carne, o sabor é um dos mais influentes sobre a satisfação (Felderhoff et al., 2020). Por meio de amostras norte-americanas, australianas e chinesas, O'Reilly et al. (2020) também identificaram que a maciez e a suculência foram bem avaliadas pelos consumidores 
mais velhos, mas a influência do gênero se demonstrou relevante apenas em respondentes norteamericanos.

O Brasil é uma das potências na produção de carne, podendo tornar-se o maior exportador do produto bovina até 2029. Apesar dos fortes impactos econômicos da pandemia da COVID-19, a estimativa produtiva para o agronegócio na produção de carnes para período 2019/20 é superior a 28 milhões de toneladas (Malafaia et al., 2020c). Em 2019, o PIB do Brasil foi de R \$ 7,3 trilhões, sendo que $8,5 \%$ oriundos do setor pecuário de corte. A produção de carne chegou a 10,49 milhões TEC, os quais $76,3 \%$ desta produção, bem como 47 mil TEC via importação, foram destinados ao mercado internos brasileiro (ABIEC, 2020).

O Brasil é o terceiro maior consumidor de carne bovina do mundo, possuindo uma média per capta de consumo de 38,37 kg/ano. Sob a ótica do consumidor, Miller (2020) relata que os consumidores percebem as diferenças entre o gosto de produtos oriundos da carne, por meios de avaliações sobre a suculência, maciez e o sabor. Sendo assim, tem-se a seguinte pergunta-problema: quais fatores referentes ao produto (carne) e ao ponto de venda são capazes de influenciar o comportamento de compra dos adeptos de carne de uma loja, em uma cidade do sul de minas?

A partir do exposto, este estudo tem como objetivo propor um modelo capaz de identificar quais aspectos relacionados à carne e ao ponto de venda influenciam a frequência de compra dos adeptos de carne em uma casa de carnes em uma cidade do sul de Minas Gerais. Para o cenário nacional, o agronegócio possui um papel relevante na economia. Sendo assim, o estudo se torna importante pelas contribuições sobre a elaboração de políticas públicas, favorecendo aos atuantes deste nicho de mercado insights referentes aos elementos da cadeia produtiva de carne brasileira. Academicamente, a pesquisa contribui para a literatura referente a uma das temáticas de marketing, especificamente, a área comportamental de consumo. Por fim, o estudo visa agregar à literatura por meio das descobertas sobre as influências do local e do produto (carne) sobre a frequência de compra dos adeptos ao consumo.

\section{CARNE: PRODUTO, MERCADO E O CONSUMO}

O desenvolvimento de pesquisas sobre tomada de decisão de compra, bem com as interações relacionais entre comprador e vendedor ocupam a centralidade na literatura de marketing empresarial e Business-to-Business (Dzever, Merdji, \& Saives, 2001). 0 processo de decisão de compra dos consumidores consiste em uma sistematização, a qual o consumidor avalia as informações que antecedem e sucedem suas atividades de aquisição (Garcia, Carvalho, Miranda, \& Bosco, 2018). 0 modelo geral deste processo de decisão se resume em cinco fases: reconhecer o problema, coletar informações, avaliar as alternativas disponíveis (pré-compra), selecionar o item desejado e a avaliação pós-compra (Marin, 2015; Putra \& Hartono, 2020). Em outras palavras é a comparação entre as diferentes opções capazes de atender suas necessidades, com base em informações obtidas por influências sociais ou experiências vivenciadas.

Há tempos alguns aspectos são apresentados como influenciadores nas atividades de compra como a necessidade, o estilo de vida, as influências culturais, as preferências de infância, atender ou imitar comportamentos grupais, recomendações, formas de substituição e, até mesmo, formas aleatórias e superficiais. Em alguns casos, é possível a ocorrência de um processo de decisão limitado, em que atividades de compra, podem não existir e/ou exigir a formulação de planos para realizar a decisão, inclusive, na primeira situação de aquisição (Olshavsky \& Granbois, 1979).

Dois aspectos são fundamentais para a formulação do processo de decisão: o volume de informações disponíveis e a motivação para tal atividade. Os consumidores tendem a começar o processo de avaliação por meio dos atributos, realizando comparações para eliminar alternativas, levando as marcas em consideração conforme o desenrolar do processo (Bettman \& Park, 1980). A probabilidade de o consumidor comprar uma marca pode ser influenciada, não só por suas experiências anteriores, mas também pela escolha da loja. No momento da compra, dois pontos corroboram para tal influência: a disponibilidade da marca e as promoções da loja (Rao, 1969). Ainda, o preço, a imagem transmitida, a pressão do tempo pela compra e o processo de decisão de compra 
são algumas das peculiaridades significativas quanto aos níveis de satisfação dos consumidores (Putra \& Hartono, 2020).

0 consumidor pode assumir cinco funções durante o processo de aquisição, sendo elas: 'o iniciador' - em que cria ou segue uma ideia de compra; 'o prescritor' - em que exerce influencias, de maneira implícita ou explicita, a decisão de compra final; 'o tomador de decisão' - é a pessoa que determina a ação de compra total ou parcial (onde, quando e o quê comprar?); 'o comprador' - aquele que exerce a ação real de aquisição do produto; e por fim, 'o consumidor' - exerce o usufruto do item em questão (Marin, 2015). Em outras palavras, o consumidor pode considerar a experiência de preparação de um novo prato culinário à base de carne e, assim, ir em busca do produto. Mediante a observação da carne no local de compra, o consumidor pode considerá-la ser de qualidade, instigandoo a comprar de tal produto. Assim, o consumidor realiza as etapas culinárias com produto e, por fim, experienciar a culinária almejada.

0 consumo de produtos de origem animal, extensivo à carne, sempre acompanhou a humanidade durante o seu processo de desenvolvimento e sobrevivência, desde os primórdios. Naquele tempo, a carne era obtida por meio das práticas de caça, as quais foram perdendo força à medida que ações de domesticação animal e habitação se desenvolviam (Souki, 2003). Consequentemente, o processo evolutivo resultou em inúmeras adaptações produtivas e comerciais, e com a disseminação do consumo de carne pelo mundo percebeu-se as influências políticas, econômicas, tecnológicas, culturais e sociais nas ações de compra e consumo do alimento (Kiran et al., 2018; Ouriveis et al., 2020; Malafaia, Biscola, \& Dias, 2020c).

Apesar da carne ser vista como um dos alimentos centrais e de importância simbólica na alimentação humana, algumas mudanças alimentares e alterações na demanda tem sido observada no decorrer dos anos (Grunert, 2006; Kratz et al., 2020). Ora por questões ligadas a saúde alimentar, ora pela preocupação com o bem-estar e saúde animal, resultando a adesão pelo consumo vegano ou vegetariano (Malafaia, et al., 2020b). É importante dizer que, popularmente, existem dois tipos de carne: a carne vermelha e a carne branca. A carne vermelha é composta por fibras de contração lenta, presentes em carnes bovinas, suínas, caprinas, ovinas, entre outras. Por outro lado, a carne branca possui fibras de contração rápida, presente em carnes de peixes, aves, anfíbios e repteis (Agarwal \& Agarwal, 2017).

No Brasil, a produção de carne no período de 1990 a 2018 aumentou em 139\%, sendo 11\% somente em 2018. Com mais de 213 milhões de cabeças, a pecuária de corte foi responsável por 8,5\% do PIB nacional em 2019, com mais de R 618 bilhões. Dentre os 10,49 milhões TEC de produção, $76,3 \%$ milhões TEC foram consumidas pelo mercado interno, além de 47 mil TEC obtidos via importação. Resultando em uma média per capta de 38,37kg/ano de consumo (ABIEC, 2020). Além disso, a previsão para a próxima década (2029/30) é um aumento produtivo maior que 23,5\%, principalmente, a carne de frango (28\%). Até 2029, o Brasil pode se tornar o maior exportador de carne bovina do mundo, possuindo como principais mercados: China, Estados Unidos, Japão e Coréia do Sul (Malafaia et al., 2020c).

Mediante o exposto, o cenário brasileiro caminha para um território amplo de oportunidades, no entanto, alguns desafios de mercado devem ser superados pelos agentes da cadeia produtiva de carne. 0 setor deve compreender os consumidores e suas percepções (Mércio, Pereira, Pereira, Zago, \& Barcellos, 2020), se tornando um fator condicional para sobrevivência e crescimento organizacional. Dentre as tendências de mercado até 2040 , alguns quesitos precisam ser melhorados, sendo eles: a imagem da pecuária aos olhos do consumidor, no que tange as questões ecológicas, bem-estar e saúde animal, consolidação da qualidade em âmbito nacional e internacional, a integração entre os canais de venda e o ambiente domésticos via internet (Malafaia et al., 2020a; 2020b).

Os consumidores esperam que as atividades de compra e consumo sejam fáceis, convenientes e, ao mesmo tempo, seguras. As carnes são alimentos não duráveis, comprados e consumidos com muita regularidade, o que induz à inúmeras percepções sensoriais. Sendo assim, as mínimas mudanças serão sensíveis aos consumidores, mesmo eles não sendo capaz de descrevê-las (Steenkamp, 1990). A busca por saúde e longevidade tem impulsionado os consumidores em aderir o consumo de produtos orgânicos, valorizando produtos ecologicamente corretos, com ausência de hormônios, corantes, conservantes e estabilizantes (Souki, 2003). 
O consumo de carne poder ser influenciado por particularidades que envolvem o desenvolvimento regional, aspectos demográficos, socioeconômicos, climáticos, qualidade alimentar e saúde do produto, gostos e hábitos pessoais, bem como a precificação (Kiran et al., 2018). Sendo assim, a utilização da estratégia de qualidade na produção de carne pode contribuir tanto nos aspectos macro e micro do consumo. Macro por oferecer melhores condições de competitividade nacional e internacional às empresas e micro por criar condições aos produtores e consumidores (Steenkamp, 1990).

O conceito de qualidade percebida é multidisciplinar, consiste em olhar a qualidade sob a ótica do consumidor (Steenkamp, 1990), podendo incluir dimensões sensoriais, saudabilidade, conveniência e as preocupações ecológicas e de bem-estar animal (Grunert, 2006). A qualidade da carne para os consumidores ultrapassou suas especificidades técnicas produtivas, já que a percepção de qualidade de um alimento pode ultrapassar as características inerentes à comida. Essa perspectiva de qualidade percebida não só depende das particularidades do consumidor e do produto, mas também da ligação entre contextos e situações as quais ocorrem a interação entre o sujeito e o alimento (Issanchou, 1996). Em outras palavras, a qualidade da carne para o consumidor está ligada à sua aceitação quanto às características diretas e indiretas ligadas a produção e comercialização do produto.

No Brasil, possíveis tendências quanto às exigências e desejos dos consumidores de carne até 2040 são relatadas, sendo eles: busca por marcas próprias de origem (frigoríficos e fazenda), variedades de cortes, características organolépticas aceitáveis e de origem orgânica, conveniência e adequação aos hábitos culturais e renda (Malafaia et al., 2020b). Ainda, dentre variáveis opcionais de carnes ofertadas pelo mercado, alguns estudos nacionais investigaram a importância da carne bovina, a qual é a mais consumida pelos consumidores (Bezerra et al., 2007), ao mesmo tempo que alguns consumidores consideram a carne de peixe a mais saudável (Kirinus et al., 2016; Ouriveis et al., 2020, Kratz et al., 2020).

As peculiaridades de um produto influenciam as percepções dos consumidores, de modo a avaliar os níveis de qualidade e o valor das alternativas que possui (Garcia et al., 2018). De modo que, o que pode intervir sobre a observação de qualidade, durante a decisão de compra até o consumo, são as particularidades do produto e do ponto de venda (Issanchou, 1996). Em suma, observar o compromisso da organização com seus clientes. As empresas devem se atentar às preferências, demandas, bem como os níveis de satisfação dos consumidores quando a qualidade do produto (Kiran et al., 2018; Mércio et al., 2020).

\section{Formulação de hipóteses de pesquisa}

A definição de qualidade para o consumidor se inicia pela observação das pistas (dicas) de qualidade e aos atributos de qualidade. As dicas são características perceptíveis aos consumidores no ponto de venda, já os atributos de qualidade são obtidos, somente, por meios das pistas de qualidade. Em suma, atributos de qualidade são o que os consumidores desejam e surgem após o consumo, podendo ser situações experienciadas anteriormente (Steenkamp, 1990). O cliente pode adquirir e consumir um produto visando os atributos de qualidade, em outras palavras, os benefícios ou consequências almejadas. Portanto, nota-se uma similaridade com os pressupostos da Teoria da Cadeia Meios-Fins, a qual relata que os atributos de um produto geram consequências ou benefícios, os quais são utilizadas como meios para se atingir estágios finais de existência (Gutman, 1982).

No que tange as dicas de qualidade, estas podem ser intrínsecas ou extrínsecas. Deste modo as intrínsecas se referem as partes físicas que fazem parte dos produtos, enquanto as extrínsecas são características tangíveis ou intangíveis relacionadas aos produtos, mas não fazem parte deles (Grunert, 2006). As peculiaridades extrínsecas podem ser utilizadas como dicas, de modo a influenciar as percepções sensoriais e hedônicas dos consumidores (Issanchou, 1996). Porém devem se originar de fontes consideradas confiáveis pelo consumidor (Grunert, 2006). A partir disso tem-se as hipóteses:

$\mathbf{H}_{1:}$ Os atributos intrínsecos (AI) da carne influenciam positivamente e, de forma significativa, a percepção quanto os atributos extrínsecos (AE) da carne; 
$\mathbf{H}_{2:}$ Os atributos intrínsecos (AI) da carne influenciam positivamente e, de forma significativa, a percepção quanto os benefícios experienciais (BE) da carne;

$\mathbf{H}_{3:}$ Os atributos extrínsecos (AE) da carne influenciam positivamente e, de forma significativa, a percepção quanto os benefícios experienciais (BE) da carne;

$\mathbf{H}_{4:}$ Os atributos extrínsecos (AE) da carne mediam positivamente a relação entre os atributos intrínsecos da carne e a percepção dos benefícios experienciais (BE) da carne;

$\mathrm{Na}$ literatura sobre comportamento do consumidor, alguns estudos relatam peculiaridades do produto carne, os quais são valorizados durante as ações de compra e consumo. Sendo assim, os aspectos foram categorizados de acordo com as definições sobre qualidade percebida, resultando na criação de três constructos sobre a carne (Tabela 1):

Tabela 1

Classificação das peculiaridades da carne

\begin{tabular}{|c|c|c|c|}
\hline $\begin{array}{l}\text { Atributos } \\
\text { Intrínsecos }\end{array}$ & Atributos Extrínsecos & $\begin{array}{c}\text { Benefícios } \\
\text { experienciais }\end{array}$ & Autores \\
\hline $\begin{array}{l}\text { Cor; quantia de } \\
\text { gordura; }\end{array}$ & $\begin{array}{l}\text { Preço; marca; país de } \\
\text { origem; loja; }\end{array}$ & --- & $\begin{array}{l}\text { Steenkamp } \\
(1990)\end{array}$ \\
\hline $\begin{array}{l}\text { Cor; baixo teor de } \\
\text { gordura; } \\
\text { marmorização; }\end{array}$ & $\begin{array}{c}\text { Marcas; selos de } \\
\text { qualidade; rotulagem; } \\
\text { comunicação; }\end{array}$ & $\begin{array}{l}\text { Conveniência de preparo; } \\
\text { segurança; bem-estar } \\
\text { animal; saudabilidade; } \\
\text { sabor; suculência; }\end{array}$ & $\begin{array}{l}\text { Issanchou } \\
\text { (1996) }\end{array}$ \\
\hline $\begin{array}{l}\text { Corte; níveis de } \\
\text { gordura; }\end{array}$ & $\begin{array}{l}\text { Preço; origem orgânica; } \\
\text { ponto de venda; } \\
\text { informativos da } \\
\text { rotulagem e no ponto de } \\
\text { venda; ausência de } \\
\text { resíduos; }\end{array}$ & $\begin{array}{c}\text { Frescor; bem-estar } \\
\text { animal; ecológico; } \\
\text { conveniência de preparo; } \\
\text { maciez; suculência; } \\
\text { saudabilidade; sabor; } \\
\text { nutritiva; confiança no } \\
\text { açougueiro; }\end{array}$ & $\begin{array}{l}\text { Grunert et al. } \\
\qquad(2002)\end{array}$ \\
\hline ------- & $\begin{array}{l}\text { Ausência de resíduos e } \\
\text { aditivos; data de } \\
\text { validade; data de } \\
\text { fabricação; procedência; } \\
\text { certificação. }\end{array}$ & Ecológicos; & Souki (2003) \\
\hline Corte; & $\begin{array}{l}\text { Origem orgânica; } \\
\text { rastreabilidade; }\end{array}$ & $\begin{array}{c}\text { Saudabilidade; } \\
\text { conveniência de preparo; } \\
\text { bem-estar animal; saúde } \\
\text { segurança; }\end{array}$ & Grunert (2006) \\
\hline $\begin{array}{l}\text { Cor; aroma (cheiro); } \\
\text { consistência (grau de } \\
\text { firmeza); gordura; }\end{array}$ & $\begin{array}{l}\text { Data de validade; data de } \\
\text { fabricação; certificação; }\end{array}$ & $\begin{array}{c}\text { Sabor; maciez; } \\
\text { suculência; frescor; } \\
\text { saudabilidade } \\
\end{array}$ & $\begin{array}{l}\text { Garcia et al., } \\
\text { (2018) }\end{array}$ \\
\hline $\begin{array}{l}\text { Corte; teor de } \\
\text { gordura; }\end{array}$ & Preço; & $\begin{array}{c}\text { Sabor; facilidade de } \\
\text { preparo; digestibilidade; } \\
\text { fonte de proteínas; }\end{array}$ & $\begin{array}{l}\text { Kratz et al. } \\
\text { (2020) }\end{array}$ \\
\hline $\begin{array}{c}\text { Raça; corte; aroma } \\
\text { (cheiro); }\end{array}$ & $\begin{array}{l}\text { Embalagem; origem; } \\
\text { marca; preço; } \\
\text { publicidade e } \\
\text { propaganda; }\end{array}$ & $\begin{array}{l}\text { Aspectos sociais e } \\
\text { religiosos; sabor; }\end{array}$ & $\begin{array}{l}\text { Ouriveis et al. } \\
\qquad(2020)\end{array}$ \\
\hline
\end{tabular}

Fonte: Dos autores (2021)

Diante das dicas de qualidade consideradas de maneira intrínsecas ou extrínsecas, tem-se a busca dos clientes em adquirir e/ou consumir um produto e experienciar visando os atributos de qualidade, em outras palavras, os benefícios ou consequências almejadas. Consequentemente, a presença dos atributos (intrínsecos e extrínsecos) e os benefícios experienciais advindos do produto podem exercer influências sobre os níveis de adesão ao produto. As informações disponíveis sobre a 
carne estão cada vez mais influenciando a qualidade percebida sobre a carne, do que suas próprias características em si (Grunert, 2006). Além disso, os consumidores não valorizam os atributos da carne de forma individual, mas sim em aglomerados, como pistas a serem seguidas para obter qualidade e benefício almejados (Garcia et al., 2018). Isso permite a construção da seguinte hipótese:

H5: Os benefícios experiencias (BE) influenciam positivamente e, de forma significativa, a frequência de compra de carne (FCC);

Por outro lado, deve ser considerando a importância dos pontos de venda, já que estes apresentam peculiaridades capazes de influenciar as atividades de compra e consumo dos clientes. As percepções, sensações e as atitudes referente a seleção, compra e consumo de produtos ou serviços são aspectos relacionados ao comportamento de consumo. Assim sendo, percebeu-se que lojas de médio porte, carnes frescas e a qualidade percebida podem ser considerados um dos pontos valorizados pelos consumidores durante a escolha do local de compra (Souček \& Turčinkova, 2015). Além disso, particularidades como a localização geográfica da loja, o leque de oferta, o nível dos preços, o comportamento dos vendedores, as formas de atendimento, o ambiente interno, a qualidade dos clientes e da publicidade também são observados (Marin, 2015).

Alguns estudos reforçam e complementam os aspectos citados. Souki (2003) identificou cinco fatores ligados ao ponto de venda considerados importantes para os consumidores. 0 primeiro fator, "conveniência e a praticidade" foi composto pelas variáveis: não ser distante de casa, rapidez no atendimento, ter uma boa localização, não ter filas na hora de pagar, facilidade de estacionamento, cordialidade no atendimento. 0 segundo fator, "imagem da empresa e funcionários" foi representado pelos aspectos aparência dos funcionários, propaganda e iluminação do estabelecimento. 0 fator "preço e condições de pagamento" foi composto pelas variáveis: forma de pagamento, prazos ofertados, promoções e preços. 0 fator "procedência dos produtos" foi composto pelas variáveis selo de procedência e presença do açougueiro no local de compra. 0 último fator, "marcas, produtos e serviços diferenciados" foi representado pelos aspectos oferecer produtos inovadores, oferecer produto importados, possibilidade de degustação do produto no local, receitas e dicas de preparo.

Souček \& Turčinkova (2015) identificaram alguns componentes de fatores considerados pelos consumidores sobre o ponto de venda. O primeiro fator, "preço e hábitos", foi composto pelas características: ofertas atualizadas nos folhetos, localização conveniente da loja, preços baixos, hábitos, quantia de mercadoria suficiente para o cotidiano e em ofertas. 0 segundo fator, "situações na loja", inclui pessoas amigáveis da loja, atendimento rápido, custos do tempo de espera no caixa, facilidade em resolver reclamações, oferta de produtos de origem local. 0 terceiro fator, "atributos qualitativos da carne", é composto pelas características facilidade de encontrar mercadoria, limpeza do layout da loja, indicação correta de preços e produtos, variedade de produtos, produtos frescos e a qualidade da mercadoria. 0 último fator, "conveniência na hora da compra", foi composto pela capacidade de estacionar junto à loja, proximidade aos pontos de parada de transporte coletivo, possibilidade de pagamentos com vale almoço e embalagens gratuitas. A partir disso, criam-se as hipóteses:

$\mathbf{H}_{6}$ : 0 constructo 'política de preços do local' (PPL) influencia positivamente e, de forma significante, a 'frequência de compra de carne' (FCC);

$\mathbf{H}_{7}$ : 0 constructo 'atendimento e a cordialidade local' (ACL) influencia positivamente e, de forma significante, a 'frequência de compra de carne' (FCC);

$\mathbf{H}_{8}$ : $\mathbf{O}$ constructo 'imagem e o comprometimento local' (ICL) influencia positivamente e, de forma significante, a 'frequência de compra de carne' (FCC);

H9: O constructo 'conveniência e praticidade local' (CPL) influencia positivamente e, de forma significante a 'frequência de compra de carne' (FCC).

Sendo assim, tem-se a apresentação do modelo estrutural utilizado neste estudo: 


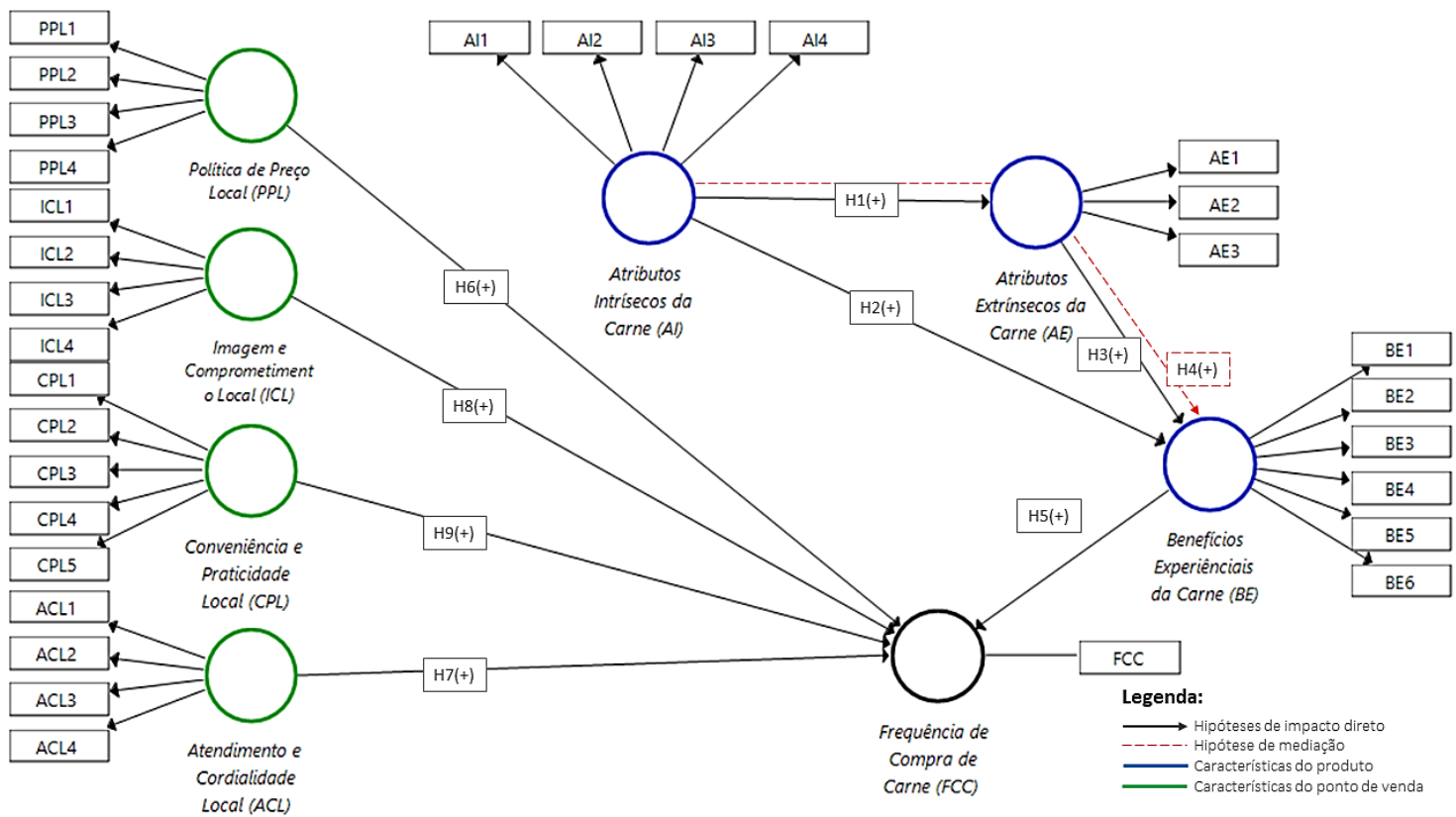

Fonte: Do autor (2021) - auxílio software Smart PLS (3ํㅗversão).

Figura 1. Modelo estrutural e hipóteses de pesquisa

Os constructos utilizados para este estudo foram gerados com base nas informações consideradas relevantes na literatura sobre a temática. Tais constructos também foram adaptados visando atender a temática e objetivos de estudo.

\section{PROCEDIMENTOS METODOLÓGICOS}

Com o objetivo de identificar os aspectos inerentes ao produto e do ponto de venda que são capazes de influenciar o comportamento de compra dos adeptos da carne de uma casa de carnes em uma cidade do sul de Minas Gerais. A empresa atua no comércio de há oito anos e conta com um corpo produtivo de oito funcionários, além do gestor e proprietário da organização. Sendo assim, a presente pesquisa caracteriza-se como um estudo de caso, pois se trata de uma investigação empírica, descrevendo e interpretando a complexidade de um fenômeno contemporâneo dentro de um caso concreto, em contexto da vida real (Yin, 2001; Martins, 2008).

Para isso, utilizou-se das abordagens de pesquisa quantitativa, descritiva e temporalidade transversal. Assim, devido a opção pela massificação dos dados e a utilização de cálculos estatísticos para as análises, o estudo visa descrever um fenômeno do mercado como a determinação da frequência de compra, por meio da coleta de dados de forma estruturada em um determinado momento situacional do mercado (Malhotra, 2011). Os dados primários foram coletados no último trimestre de 2019, utilizou-se do método levantamento de dados survey por meio de um questionário estruturado.

O método de levantamento survey visa obter características de uma população por descrições quantitativas, podendo ser realizado de forma presencial (face-a-face) (Freitas et al., 2000). É importante dizer que as variáveis utilizadas neste estudo eram estruturadas de múltipla escolha (Malhotra, 2011). As variáveis eram apresentadas sob uma escala de concordância de 5 pontos, tendo polos opostos "nenhuma importância" e "muito importante", adaptadas a partir do questionário estruturado utilizado por Souki (2003). A partir disso, mediante as informações obtidas na literatura, tais variáveis foram agrupadas, resultando na formação dos constructos utilizados neste estudo, conforme no Tabela 2: 
Tabela 2

Constructos elaborados para a realização do estudo

\begin{tabular}{|c|c|}
\hline \multicolumn{2}{|r|}{ Constructos sobre o local de compra } \\
\hline $\begin{array}{l}\text { Conveniência e } \\
\text { Praticidade Local } \\
\text { (CPL) }\end{array}$ & $\begin{array}{l}\text { CPL1. Possuir atendimento ágil (rápido); } \\
\text { CPL2. Possuir boa localização } \\
\text { CPL3. Possuir facilidades de estacionamento } \\
\text { CPL4. Oferecer entregas em domicílio; } \\
\text { CPL5. Oferecer produtos complementares (farofa, carvão, sal, bebidas); }\end{array}$ \\
\hline $\begin{array}{l}\text { Políticas de Preços } \\
\text { do Local (PPL) }\end{array}$ & $\begin{array}{l}\text { PPL1. Possuir preços acessíveis; } \\
\text { PPL2. Possuir promoções e propagandas atrativas; } \\
\text { PPL3. Oferecer prazos e formas de pagamento favoráveis (cartão, } \\
\text { parcelamento, cheque); } \\
\text { PPL4. Possui níveis toleráveis de fila mediante o pagamento; }\end{array}$ \\
\hline $\begin{array}{l}\text { Imagem e } \\
\text { Comprometimento } \\
\text { Local (ICL) }\end{array}$ & $\begin{array}{l}\text { ICL1. Possuir boa aparência e higiene no interior da loja } \\
\text { ICL2. Possuir funcionários com boa aparência e higiene } \\
\text { ICL3. Possuir facilidade em encontrar o produto que preciso } \\
\text { ICL4. Possuir responsabilidade social, ecológica e cultural }\end{array}$ \\
\hline $\begin{array}{l}\text { Atendimento e } \\
\text { Cordialidade Local } \\
\qquad \text { (ACL) }\end{array}$ & $\begin{array}{l}\text { ACL1. Possuir bom relacionamento com os funcionários da loja; } \\
\text { ACL2. Possuir bom relacionamento com o dono da loja; } \\
\text { ACL3. Possuir boa iluminação } \\
\text { ACL4. Oferecer a possiblidade de cortes na hora; }\end{array}$ \\
\hline \multicolumn{2}{|r|}{ Constructos sobre o produto (carne) } \\
\hline $\begin{array}{l}\text { Atributos } \\
\text { Intrínsecos da Carne } \\
\text { (AI) }\end{array}$ & $\begin{array}{l}\text { AI1. Odor Agradável (possuir bom cheiro) } \\
\text { AI2. Apresenta boa Coloração (cor) } \\
\text { AI3. Apresenta baixo nível de gordura } \\
\text { AI4. Ser Marmorizada (ter gordura entremeada na carne) }\end{array}$ \\
\hline $\begin{array}{l}\text { Atributos } \\
\text { Extrínsecos da } \\
\text { Carne } \\
(\mathrm{AE})\end{array}$ & $\begin{array}{l}\text { AE1. Não apresenta resíduos (antibióticos, anabolizantes, corantes, etc.) } \\
\text { AE2. Ser bem embalada (vácuo, bandejas de isopor) } \\
\text { AE3. Possui certificação de qualidade e procedência nos produtos }\end{array}$ \\
\hline $\begin{array}{l}\text { Benefícios } \\
\text { Experienciais da } \\
\text { Carne } \\
\text { (BE) }\end{array}$ & $\begin{array}{l}\text { BE1. Ser Fresca } \\
\text { BE2. Ser Macia } \\
\text { BE3. Ser Suculenta (antes e pós preparo) } \\
\text { BE4. Ser saborosa após o preparo } \\
\text { BE5. Pode ser usada em diferentes pratos culinários (versátil) } \\
\text { BE6. Apresenta boa aparência, apresentando-se estar saudável }\end{array}$ \\
\hline
\end{tabular}

Fonte: Adaptado de Souki (2003)

A pesquisa foi realizada junto aos clientes de uma Casa de Carnes. Deste modo, àqueles que saíssem do estabelecimento portando qualquer produto comercializado no local sob seus domínios eram convidados a participar da pesquisa, e assim realizar o autopreenchimento do questionário. Neste momento, o pesquisador se afastava do participante, se aproximando somente para sanar suas dúvidas ou após o término do formulário. Após entregar o questionário preenchido, como forma de agradecimento pela participação, os participantes recebiam um bilhete, o qual lhes concediam o direito de participação a um sorteio de um Kit Churrasco. Malhotra (2011) relata que o uso de incentivos pode contribuir para o aumento nos índices de participação.

Quando ao método de seleção de amostragem, este pode ser considerado como nãoprobabilístico por conveniência, selecionado aqueles que estiveram no dia e horário da realização da coleta de dados (Malhotra 2011). Salienta-se que no formulário existiam duas questões utilizadas como filtro, as quais foram inseridas entre as variáveis de estudo. Tais questões solicitavam aos entrevistados que assinalassem uma alternativa específica (e.g. para fins de controle, assinale a alternativa " $\mathrm{x}$ " nesta questão), visando averiguar os níveis de atenção dos respondentes durante a respostas. Os questionários com respostas contraditórias às perguntas filtro inseridas foram desconsiderados e excluídos da amostra. Além disso, a fim de caracterizar a amostra, os respondentes 
foram indagados com questões demográficas, sociodemográfica e comportamentais sobre o consumo de carne.

\section{Critérios para análise dos dados}

A pesquisa contou com 196 questionários totais respondidos. Todavia, 12 questionários foram retirados por inconsistência de resposta mediante às perguntas filtro do estudo, resultando em 184 respondentes. As 184 respostas foram tabuladas no software Excel@ e, posteriormente, importados para o software IBM SPSS Statistics ${ }^{\circledR}$. Além disso, todos os casos com missing foram excluídos da amostra e, assim, 178 respondentes foram considerados válidos para os processos de análise dos dados. Assim, as hipóteses e modelo de equações estruturais propostos nesta pesquisa foram operacionalizadas no software Smart PLS® ( $3^{\text {a }}$ versão).

Para o processo de análise foi utilizada a Modelagem de Equações Estruturais. Este modelo possui como característica, o uso conjuntivo de técnicas estatísticas multivariadas em uma ou mais variáveis dependentes e independentes, contínuas ou discretas (Tabachnick \& Fidell, 1996). Salientase que existem dois modelos escalares de mensuração em SEM: reflexivos ou formativos. Enquanto no modelo formativo as variáveis latentes (constructos) surgem a partir dos indicadores, ou seja, motivam o surgimento de constructos, os modelos reflexivos caracterizam-se pela direção de causalidade, os construtos resultam nos indicadores observados (Hair Jr. et al. 2014, Mendonça et al. 2018). Em outras palavras, as variáveis do formulário são explicadas pelos constructos. Sendo assim, o modelo deste estudo utilizado no presente estudo pode ser considerado reflexivo.

\section{ANÁLISE E DISCUSSÃO DOS RESULTADOS}

Inicialmente fez-se a caracterização dos participantes quanto as informações sociodemográficas. Assim sendo, dentre os 178 respondentes válidos, a maioria é do sexo masculino $(53,9 \%)$ e apresentam uma faixa de idade 31 a 40 anos $(26,4 \%)$. Além disso, 50\% dos participantes são casados, sendo que a maioria se enquadra na faixa de renda de $R \$ 1.500,00$ até $R \$ 3.000,00$. Além disso, observa-se um alto nível de escolaridade dos participantes, sendo que a maioria $(53,7 \%)$ relata possuir nível superior ou mais.

Os resultados obtidos foram separados em dois processos. Primeiro, a avaliação do modelo de mensuração reflexivo proposto para identificar as peculiaridades do produto e do local de compra que são capazes de influenciar a frequência de compra dos consumidores, utilizando-se da modelagem em equações estruturais. A segunda etapa se refere a análise do modelo estrutural, bem como a possível comprovação das hipóteses sugeridas para o estudo. Sendo assim, por meio da utilização dos parâmetros de ponderações em coeficientes de caminho, utilizando os critérios de parada de $1 \times 10^{-7} \mathrm{e}$ o número máximo de 300 interações permitidas, o modelo convergiu antes da $12^{\underline{a}}$ interação.

No que se refere a avaliação dos modelos de medição reflexivos, em que os indicadores são oriundos dos constructos, os seguintes aspectos devem ser observados: confiabilidade composta, outer loading, validade convergente (AVE), alfa de Cronbach e o teste Fornell-Larcker. Por meio dos índices, tais informações contribuem quanto a identificação e adequação do modelo referente a qualidade de mensuração, forme a Tabela 3:

Tabela 3

Avaliação do modelo de medição reflexivo

\begin{tabular}{|c|c|c|c|c|c|c|}
\hline Constructos & & $\begin{array}{c}\text { Outer } \\
\text { Loading }\end{array}$ & $\begin{array}{c}\text { Confiabilidade } \\
\text { composta } \\
\end{array}$ & AVE & $\begin{array}{c}\text { Alfa de } \\
\text { Cronbach } \\
\end{array}$ & $\begin{array}{l}\text { Fornell- } \\
\text { Larcker }\end{array}$ \\
\hline Parâmetros & & $>0,7$ & $>0,7$ & $>0,5$ & $>0,7$ & - \\
\hline $\begin{array}{l}\text { Atributos } \\
\text { Extrínsecos }\end{array}$ & $\begin{array}{l}\text { AE2 } \\
\text { AE3 }\end{array}$ & $\begin{array}{l}0,877 \\
0,685\end{array}$ & 0,762 & 0,619 & 0,400 & 0,787 \\
\hline $\begin{array}{l}\text { Atributos } \\
\text { Intrínsecos }\end{array}$ & $\begin{array}{l}\text { AI1 } \\
\text { AI2 }\end{array}$ & $\begin{array}{l}0,808 \\
0,848\end{array}$ & 0,814 & 0,686 & 0,543 & 0,828 \\
\hline $\begin{array}{l}\text { Benefícios } \\
\text { Experienciais }\end{array}$ & $\begin{array}{l}\text { BE1 } \\
\text { BE3 } \\
\text { BE4 }\end{array}$ & $\begin{array}{l}0,770 \\
0,541 \\
0,686\end{array}$ & 0,799 & 0,504 & 0,672 & 0,710 \\
\hline
\end{tabular}




\begin{tabular}{|c|c|c|c|c|c|c|}
\hline \multicolumn{2}{|l|}{ Constructos } & $\begin{array}{c}\text { Outer } \\
\text { Loading }\end{array}$ & $\begin{array}{l}\text { Confiabilidade } \\
\text { composta }\end{array}$ & AVE & $\begin{array}{c}\text { Alfa de } \\
\text { Cronbach }\end{array}$ & $\begin{array}{l}\text { Fornell- } \\
\text { Larcker }\end{array}$ \\
\hline \multirow{4}{*}{$\begin{array}{l}\text { Atendimento e } \\
\text { Cordialidade Local }\end{array}$} & BE6 & 0,812 & & & & \\
\hline & ACL1 & 0,856 & \multirow{3}{*}{0,842} & \multirow{3}{*}{0,641} & \multirow{3}{*}{0,720} & \multirow{3}{*}{0,800} \\
\hline & ACL2 & 0,821 & & & & \\
\hline & ACL3 & 0,717 & & & & \\
\hline \multirow{3}{*}{$\begin{array}{l}\text { Conveniência e } \\
\text { Praticidade Local }\end{array}$} & CPL1 & 0,820 & \multirow{3}{*}{0,771} & \multirow{3}{*}{0,531} & \multirow{3}{*}{0,579} & \multirow{3}{*}{0,729} \\
\hline & CPL2 & 0,645 & & & & \\
\hline & CPL3 & 0,711 & & & & \\
\hline \multicolumn{7}{|l|}{ Imagem e } \\
\hline $\begin{array}{l}\text { Comprometimento } \\
\text { do Local }\end{array}$ & ICL4 & 1,000 & 1,000 & 1,000 & 1,000 & 1,000 \\
\hline \multirow{2}{*}{$\begin{array}{l}\text { Política de Preços } \\
\text { do Local }\end{array}$} & PPL1 & 0,837 & \multirow{2}{*}{0,752} & \multirow{2}{*}{0,604} & \multirow{2}{*}{0,350} & \multirow{2}{*}{0,777} \\
\hline & PPL3 & 0,713 & & & & \\
\hline $\begin{array}{l}\text { Frequência de } \\
\text { Compra de Carne }\end{array}$ & FCC & 1,000 & 1,000 & 1,000 & 1,000 & 1,000 \\
\hline
\end{tabular}

Fonte: Do autor (2021) - auxílio software Smart PLS (3av versão).

A cargas externas (outer loading) dos indicares devem ser estatisticamente significativas, superiores ao valor de 0,708 (Hair Jr. et al., 2014). Os valores acima do índice preconizado pelo autor indicam que tais indicadores possuem similaridade quanto ao fenômeno inferido pelo constructo. Mediante o exposto, neste estudo, todos os indicadores com índices menores que 0,4 foram excluídos de seus respectivos constructos. No entanto, aqueles com valores maiores que 0,4 e menores que 0,7 foram removidos de forma a aumentar e atender os índices de confiabilidade composta e AVE (Bido \& Silva (2019).

Devido à falta de representatividade quanto aos critérios, os seguintes indicadores foram removidos de seus constructos: 'atributos extrínsecos' (AE1), 'atributos intrínsecos' (AI3 e AI4), 'benefícios experienciais' (BE2 e BE5), 'conveniência e praticidade local' (CPL4 e CPL5), 'política de preço local' (PPL2 e PPL4), 'imagem e comprometimento local' (ICL1, ICL2 e ICL3) e 'atendimento e cordialidade local' (ACL4). Os demais indicadores com valores inferiores a 0,7 foram mantidos devido a validade de conteúdo (Tabela 3 ).

Utilizada para identificar a confiabilidade e a existência de vieses na amostragem de respostas, a confiabilidade composta com valores maiores que 0,7 são considerados satisfatórios (Hair Jr. et al., 2014). Conforme destaca a Tabela 3, o menor valor para confiabilidade composta obtido se refere ao constructo 'políticas de preço local' (PPL1 e PPL3) com 0,752. Por outro lado, o maior valor se refere aos constructos 'frequência de compra de carne' (FCC) e 'imagem e comprometimento local' (ICL4), ambos com 1,000, porém, tais constructos são ligados à apenas um indicador. Sendo assim, 0,842 foi o maior índice apresentado em construtos com mais de um indicador, o qual pertencente ao constructo "atendimento e cordialidade local'.

Os índices de validade convergente (AVE), ou variância média extraída, para serem considerados satisfatórios devem possuir valores superiores a 0,5 (Fornell \& Larcker, 1981). Deste modo, todos constructos utilizados apresentaram valores maiores que 0,5. Em suma, o menor valor obtido $(0,504)$ se refere ao constructo 'benefícios experienciais' (BE1, BE3, BE4 e BE6), já o maior valor $(0,686)$ se refere ao constructo 'atributos intrínsecos' (AI1 e AI2). Assim, pode-se dizer que os constructos explicam mais de $50 \%$ da variância dos itens.

A validade discriminante se refere as diferenças de um construto para os outros constructos, quanto a medição do fenômeno. Deste modo, para testar a validade discriminante é preciso que a correlação entre os constructos seja inferior a raiz quadrada da AVE (Hair Jr. et al., 2014; Mendonça et al., 2018). Observando este critério, todos os valores obtidos pela raiz quadrada da AVE (FornellLarcker) são superiores aos valores da variância media extraída (AVE).

Por outro lado, Henseler, Ringle e Sarstedt (2014) propuseram que haverá distinção entre os constructos quando os valores de heterotraço-monotraço (HTMT) forem inferiores ao valor de 0,85. Assim, todos os valores referentes as relações entre cada constructos também apresentaram valores inferiores ao preconizado, com exceção em duas relações: o primeiro, com 0,982 , refere a interação 
entre 'atributos internos' $\rightarrow$ 'benefícios experienciais', já o segundo, a relação entre 'políticas de preço local' $\rightarrow$ 'atributos extrínsecos', com 0,893. A justificativa é que $\mathrm{AI} \rightarrow \mathrm{BE}$ são de primeira e segunda ordem, o que justifica tal complicação quanto a validade discriminante.

Adiante, a grande maioria dos índices referentes ao alfa de Cronbach foram inferiores ao valor de referência de 0,7, apena o fator 'atendimento e cordialidade local', com 0,720, atingiu este parâmetro. A justificativa se dá pelo alfa de Cronbach avaliar o constructo como um todo, em outras palavras, o valor pode ter sido comprometido e influenciado pelo volume de indicadores representantes. Adiante, após a avaliação do modelo de medição reflexivo, inicia-se o processo de análise do modelo estrutural e o teste das hipóteses levantadas para este estudo. Em suma, é a avaliação das relações diretas e indiretas entre os constructos do modelo (Nery et al., 2020). A Tabela 4 apresenta os valores obtidos referentes aos testes de hipóteses, multicolinearidade, entre outros:

\section{Tabela 4}

Síntese de análise do modelo e hipóteses de estudo

\begin{tabular}{lcccccccc}
\hline $\begin{array}{c}\text { Relação entre } \\
\text { constructos }\end{array}$ & VIF & $\mathbf{F}^{2}$ & $\begin{array}{c}\text { Coeficiente } \\
\text { de } \\
\text { Caminhos }\end{array}$ & $\begin{array}{c}\text { Desvio } \\
\text { Padrão }\end{array}$ & $\begin{array}{c}\text { Teste } \\
\boldsymbol{t}\end{array}$ & $\begin{array}{c}\text { Valor } \\
\boldsymbol{P}\end{array}$ & Hipóteses & $\begin{array}{c}\mathbf{R}^{2} \\
\text { ajustado }\end{array}$ \\
\hline $\mathrm{H}_{1:} \mathrm{AI} \rightarrow \mathrm{AE}$ & 1,000 & 0,188 & 0,397 & 0,067 & 5,926 & $0,000^{* * *}$ & Confirmada & 0.153 \\
\hline $\mathrm{H}_{2:} \mathrm{AI} \rightarrow \mathrm{BE}$ & 1,188 & 0,420 & 0,548 & 0,103 & 5,349 & $0,000^{* * *}$ & Confirmada & \\
$\mathrm{H}_{3:} \mathrm{AE} \rightarrow \mathrm{BE}$ & 1,188 & 0,037 & 0,162 & 0,085 & 1,920 & $0,055^{*}$ & Confirmada & 0.391 \\
$\mathrm{H}_{4:} \mathrm{AI} \rightarrow \mathrm{AE} \rightarrow \mathrm{BE}$ & - & - & 0,064 & 0,038 & 1,678 & $0,093^{*}$ & Confirmada & \\
\hline $\mathrm{H}_{5:} \mathrm{BE} \rightarrow \mathrm{FCC}$ & 1,274 & 0,009 & 0,104 & 0,090 & 1,152 & 0,249 & Não & \\
$\mathrm{H}_{6:} \mathrm{PPL} \rightarrow \mathrm{FCC}$ & 1,191 & 0,003 & $-0,057$ & 0,101 & 0,554 & 0,580 & Não & \\
$\mathrm{H}_{7:} \mathrm{ACL} \rightarrow \mathrm{FCC}$ & 1,252 & 0,018 & 0,145 & 0,079 & 1,804 & $0,071^{*}$ & Confirmada & 0.044 \\
$\mathrm{H}_{8:} \mathrm{ICL} \rightarrow \mathrm{FCC}$ & 1,253 & 0,001 & $-0,037$ & 0,093 & 0,393 & 0,695 & Não & \\
$\mathrm{H}_{9:} \mathrm{CPL} \rightarrow \mathrm{FCC}$ & 1,260 & 0,018 & 0,143 & 0,087 & 1,612 & 0,107 & Não & \\
\hline
\end{tabular}

Nota: ${ }^{* *}$ Significante a $1 \%$; ${ }^{* *}$ Significante a $5 \%$; *Significante a $10 \%$

Fonte: Do autor (2021) - auxílio software Smart PLS (3ํㅡ versão).

O primeiro passo realizado foi o teste de multicolinearidade, o qual torna-se aceitável um valor inferior a 5 (Hair Jr. et al., 2014). A partir disso, os resultados dos fatores de inflação de variância (VIF) apontam que o maior valor obtido se refere as relações entre os constructos: 'benefícios experienciais' $\rightarrow$ 'frequência de compra de carne', com valor de 1,274. Sendo assim, observa-se a inexistência de quaisquer problemas de multicolinearidade. Ou seja, os constructos não são 'iguais' e nem mensuram, de forma semelhante, a mesma parte do modelo (Nery et al., 2020).

Visando identificar a significância e relevância entre os relacionamentos existentes no modelo estrutural, utilizou-se da análise Bootstrapping com 10 mil subamostras e limite de significância a 5\%. Assim, o grau de explicação da variância do constructo alvo apresentou um valor de $\mathrm{R}^{2}$ igual a 0,071 $(0,044$ ajustado). Isso significa que $7 \%$ da variância dos resultados sobre 'frequência de compra de carne' são explicadas, de forma fraca, pelos constructos referentes ao local de compra: 'atendimento e cordialidade', 'imagem e comprometimento', 'política de preço', 'conveniência e praticidade', bem como os 'benefícios experienciais da carne'.

$\mathrm{O}$ constructo 'benefícios experienciais' apresentou um $\mathrm{R}_{2}$ de 0,398 (0,391 ajustado). Isso significa que 39\% da variância sobre esse constructo é influenciada pelos atributos 'intrínsecos' e 'extrínsecos' da carne. Além disso, o outro aspecto observado se refere ao 'atributo extrínseco da carne' evidenciando um valor de $\mathrm{R}_{2}$ de 0,158 (0,153 ajustado), ou seja, $15 \%$ da variância é influenciada pelos 'atributos internos da carne'. Sendo assim, a Figura 2 informa os coeficientes de determinação $\left(R^{2}\right)$ e a significância dos coeficientes de caminhos obtidos no modelo: 


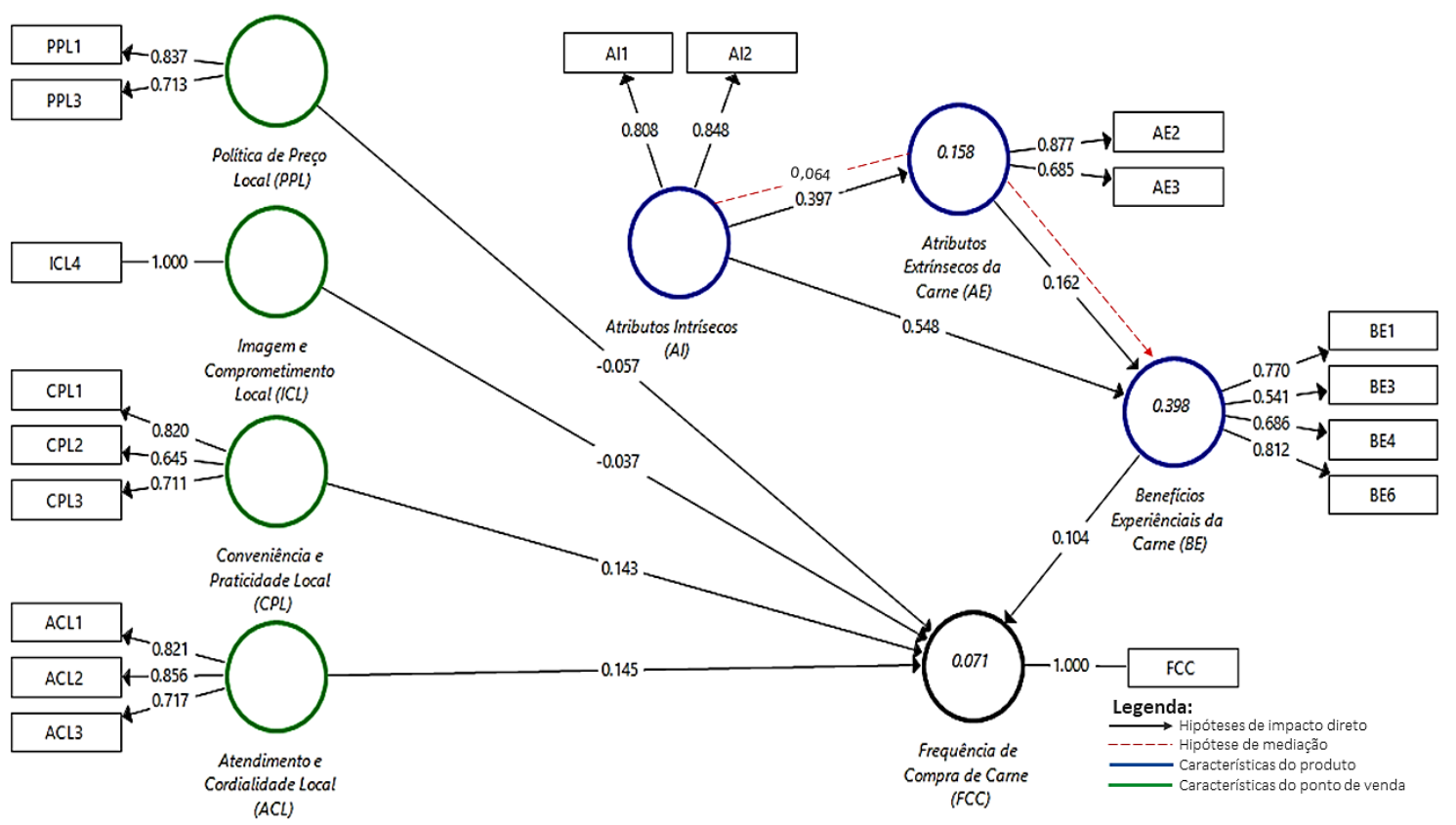

Fonte: Do autor (2021) - auxílio software Smart PLS (3를ersão).

Figura 2. Modelo estrutural

As hipóteses $\left(\mathrm{H}_{1}\right.$ e $\left.\mathrm{H}_{2}\right)$, positivas, referentes aos 'atributos intrínsecos da carne' foram confirmados pelos dados e se revelaram de forma significante a $1 \%$. Sendo assim, a relação entre os constructos $\mathrm{AI} \rightarrow \mathrm{AE}$ e $\mathrm{AI} \rightarrow \mathrm{BE}$, apresentaram o $p$-valor de 0,000 , bem como os coeficientes de caminhos (positivos) de 0,397 e 0,548, respectivamente. Confirmando que as características internas da carne (AI), sendo elas: ter um bom odor e uma boa coloração, influenciam positivamente a percepção do consumidor sobre o fato de ser bem embalada, certificações de qualidade e procedência (atributos extrínsecos), bem como sobre as percepções de saudabilidade, frescor, a suculência (antes e após preparo) e o sabor após o preparo (benefícios experienciais).

Em suma, quanto mais positivo for a coloração e o cheiro, maior será a percepção do consumidor sobre certificação, qualidade, procedência, embalagem, saudabilidade, boa aparência, suculência, frescor e sabor do produto. Issanchou (1996) relata que as peculiaridades extrínsecas podem ser utilizadas como dicas, de modo a influenciar as percepções sensoriais e hedônicas dos consumidores. Assim, a $\mathrm{H}_{3}$ referente a relação positiva entre $\mathrm{AE} \rightarrow \mathrm{BE}$, a qual também foi confirmada. $\mathrm{A}$ relação é tida como significante a $10 \%$ com um $p$-valor de 0,055 e coeficientes de caminho positivo de 0,162. Ou seja, os 'atributos extrínsecos da carne' como embalagem, certificação de qualidade e procedência, influenciam de forma positiva os 'benefícios experienciais da carne'.

No que tange a $\mathrm{H}_{4}$, a qual se refere ao efeito positivo de mediação do constructo 'atributos extrínsecos da carne' na relação entre 'atributos intrínsecos' $\rightarrow$ 'benefícios experienciais'. Têm-se a validação da hipótese e a percepção de um efeito de mediação parcial com p-valor de 0,093 e coeficiente de caminho (positivo) de 0,064 . Sendo assim, na medida que o consumidor se depara com as características intrínsecas (AI), as características extrínsecas da carne (AE) tendem a impulsionar sua percepção sobre os 'benefícios experienciais'. Sendo assim, tais descobertas corroboram com Garcia et al., (2018), o qual diz que os consumidores não valorizam os atributos da carne de forma individual, mas sim em aglomerados, como pistas a serem seguidas para obter qualidade e benefício almejados.

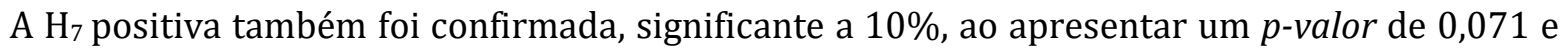
um coeficiente de caminho, positivo, de 0,145. Sendo assim, tem-se que, na medida que há um aumento quanto a qualidade de 'atendimento e cordialidade do local' referente a iluminação, bem como a convivência e a construção de um bom relacionamento do consumidor com o proprietário e funcionários da loja, a tendência é de influenciar positivamente a 'frequência de compra de carne'. 
Todavia, dois constructos apresentaram índices de relações negativas para coeficientes de caminho quanto à 'frequência de compra', sendo eles: política de preço local', com -0,057 e o 'imagem e comprometimento local', com -0,037. No que se refere a 'política de preço', percebe-se uma influência negativa quanto 'frequência de compra de carne'. Sendo assim, na medida que tais políticas de precificação, bem como de imagem e comprometimento são aplicadas exercem uma influência negativa sobre a frequência de compra. 0 que significa que pode indicar que tais aspectos não são considerados relevantes para os respondentes participantes da pesquisa.

Além dos coeficientes de caminho e determinação $\left(\mathrm{R}^{2}\right)$ é interessante mensurar o efeito, por meio do indicador $\mathrm{F}^{2}$. Ou seja, identificar o tamanho do efeito de $\mathrm{F}^{2}$ sobre $\mathrm{R}^{2}$. Segundo Hair et al. (2014), os seguintes valores devem ser seguidos: menor que 0,02 , indica pouco efeito; valores de 0,15 a 0,35 , indicam efeito moderado (médio efeito) e acima de 0,35 simbolizam um grande efeito. Sendo assim, tem-se o valor de 0,188 para 'atributo intrínseco'(AI), o que indica que o feito deste construto tem médio efeito sobre o $\mathrm{R}^{2}$ do constructo 'atributo extrínseco da carne' (AE).

Ao analisar o efeito de $\mathrm{F}^{2}$ dos constructos 'atributos intrínsecos (AI)' com 0,420, e 'extrínsecos (AE)' com 0,037, sobre o $\mathrm{R}^{2}$ do constructo 'benefícios experienciais', percebe-se que o constructo 'atributo interno' é o que mais influência. No que se refere aos efeitos dos valores de $\mathrm{F}^{2}$ referentes aos constructos 'benefícios experienciais' $(0,009)$, 'política de preço local' $(0,003)$, 'atendimento e cordialidade local' $(0,018)$, 'imagem e comprometimento local' $(0,001)$ e 'conveniência e praticidade local' $(0,018)$ sobre o $\mathrm{R}^{2}$ do constructo 'frequência de compra de carne', percebeu-se que o constructo 'atendimento e cordialidade local' é o que mais contribui e possui um médio efeito.

\section{CONSIDERAÇÕES FINAIS}

Com objetivo de propor um modelo estrutural capaz identificar quais aspectos referente ao ponto de venda e ao produto (carne) são capazes de influenciar a frequência de compra de carne, realizou-se uma pesquisa com os clientes de uma casa de carnes situada em uma cidade do sul de Minas Gerais. Sendo assim, o estudo apresentou o uso da modelagem em equações estruturais, em que as variáveis foram representadas por quatro constructos sobre o local de compra e três sobre o produto (carne). Todavia, foi possível identificar, de forma precisa, a relação entre tais aspectos e, ao mesmo tempo, contribuir para a literatura sobre a temática de marketing e comportamento do consumo.

Inicialmente o estudo identificou as características intrínsecas da carne como 'boa coloração' e o 'odor agradável', ambos influenciam $(0,397)$ de forma positiva e significante $(0,000)$ as percepções sobre a características extrínsecas da carne como 'ser bem embalada' e 'certificações de qualidade e procedência'. Além do alto valor de $\mathrm{F}^{2}(0,420)$, tal influência $(0,548)$, positiva e significante $(0,000)$, se torna ainda mais relevante quando se refere aos 'benefícios experienciais' obtidos por meio do produto como ser uma carne fresca, suculenta (antes e após o preparo), saborosa (após o preparo), boa aparência e saudabilidade. Isso significa que o gestor da organização precisa estar atento as características intrínsecas (cor e odor), as quais se tornam pilares para observações positivas quanto aos benefícios e aspectos adicionais ao produto (AE). A identificação sobre a importância desses indicadores, inclusive, favorece a formulação de estratégia de marketing e vendas.

Os atributos externos também influenciam $(0,162)$ de forma positiva e significante $(0,055)$ quanto a percepção sobre os benefícios experienciais. Da mesma forma, também é responsável por mediar $(0,064)$ de forma positiva e significante $(0,093)$ a relação entre as características internas e os benéficos experiencias. Ou seja, isso significa que aspectos como embalagem, certificação de qualidade e procedência afetam a percepção dos consumidores quanto ao frescor, suculenta (antes e após o preparo), saborosa (após o preparo), boa aparência e saudabilidade. Sendo assim, uma alternativa interessante, poderia ser a criação de embalagem personalizada e, assim, inserir informações sobre as origens dos produtos e opções de receitas culinárias, as quais podem produzir resultados positivos quanto a frequência de compra.

Dentre as características referentes ao ponto de venda, este estudo identificou que 'atendimento e cordialidade local' exerce influência $(0,018)$ de forma positiva e significante $(0,071)$ sobre a frequência de compra de carne. Ou seja, além de uma boa iluminação, o bom relacionamento 
com os funcionários e o proprietário da loja exerce influência positiva quando a frequência de compra. Percebe-se então que os clientes do estabelecimento valorizam a boa convivência e socialização com os envolvidos na operacionalização da organização. Pode-se inferir que tal valorização pode ser motivada por questões de segurança pessoal e confiança.

Este estudo também poder fornecer insight para os participantes da cadeia produtiva de carne, nacional e regional contribuindo para as contribuições gerenciais. Academicamente, o estudo contribui para os estudos que envolvem análise única local sobre comportamento de consumo e marketing. Consequentemente, isso exige a necessidade de uma nova replicação e testar sua efetividade. Além disso, as hipóteses aqui propostas, as quais não foram confirmadas podem ser (re)utilizadas em novas replicação de estudo, adaptadas ou não, sob outras unidades e óticas de análises distintas.

\section{Agradecimentos}

Esta pesquisa teve apoio da Fundação de Amparo à Pesquisa do Estado de Minas Gerais (FAPEMIG).

\section{Referências}

ABIEC. (2020). Perfil da Pecuária no Brasil 2020. Beef Report, 1-49. https://www.cicarne.com.br/wpcontent/uploads/2020/05/SUM\%C3\%81RIO-BEEF-REPORT-2020_NET.pdf

Agarwal, N. K., \& Agarwal, S. K. (2017). Red meat consumption and cardiovascular disease. Discovery Review. 53(262), 519-525.

Bettman, J. R., \& Park, C. W. (1980). Effects of prior knowledge and experience and phase of the choice process on consumer decision processes: A protocol analysis. Journal of Consumer Research, $7(3), 234-248$.

Bezerra, J. M. M., Cavalcante Neto, A., Silva, L. P. G., Lui, J. F., Rodrigues, A. E., \& Martins, T. D. D. (2007). Caracterização do consumidor e do mercado da carne suína na microrregião de Campina Grande, Estado da Paraíba. Ciência Animal Brasileira, 8(3), 485-494.

Bido, D. S., \& Silva, D. (2019). SmartPLS 3: especificação, estimação, avaliação e relato. Administração: Ensino e Pesquisa, 20(2), 488-536.

Cipriano, L. C., Siqueira, H. P. G., Messias, C. T., Lima, E. F., Medeiros, E. S., Hoppe, I. B. A. L., \& Siqueira, A. B. (2021). Perfil do consumidor de carne bovina no Estado de Roraima. Brazilian Journal of Development, 7(1), 1849-1864.

Dudinskaya, E.C., Naspetti, S., Arsenos, G., Caramelle-Holtz, E., Latvala, T., Martin-Collado, D., Orsini, S., Ozturk, E., \& Zanoli, R. 2021. European Consumers' Willingness to Pay for Red Meat Attributes. Preprints, 1-17. doi: 10.20944/preprints202101.0370.v1.

Dzever, S., Merdji, M., \& Saives, A. L. (2001). Purchase decision making and buyer-seller relationship development in the French food processing industry. International Journal Supply Chain Management, 6(5), 216-229.

Felderhoff, C., Lyford, C., Malaga, J., Polkinghorne, R., Brooks, C., Garmyn, A., \& Miller, M. (2020). Beef quality preferences: factors driving consumer satisfaction. Foods, 9(3), 289-311.

Fornell, C., \& Larcker, D. F. (1981), Evaluating structural equation models with unobservable variables and measurement error. Journal of marketing research, 18(1), p. 39-50.

Frank, S. M., Jaacks, L. M., Batis, C., Vanderlee, L., \& Taillie, L. S. (2021). Patterns of Red and Processed Meat Consumption across North America: A Nationally Representative Cross-Sectional Comparison of Dietary Recalls from Canada, Mexico, and the United States. International Journal of Environmental Research and Public Health, 18(1), 357.

Freitas, H., Oliveira, M., Saccol, A. Z., \& Moscarola, J. (2000). 0 método de pesquisa survey. Revista de Administração, 35(3), 105-112.

Garcia, S. F. A., Carvalho, D. T. de., Miranda, C. de. S., \& Bosco, B. R. M. (2018). Quais os Sinais de Carne Macia e Saborosa? Análise dos atributos da carne bovina que, no momento da compra, melhor sinalizam os benefícios mais desejados pelo consumidor. Revista Brasileira de Marketing, 17(4), 487-501. 
Gutman, J. (1982). A Means-End Chain Model Based on Consumer Categorization Processes. Journal of Marketing, 46(2), 60-72.

Grunert, K. G. (2006). Future trends and consumer lifestyles with regard to meat consumption. Meat Science, 74(1), 149-160.

Grunert, K. G., Skytte, H., Esbjerg, L., Poulsen, C. S., \& Hviid, M. (2002). Dokumenteret kødkvalitet: slutrapport. MAPP Project Paper, 1-81.

Hair, J. F., Hult, G. T. M., Ringle, C., \& Sarstedt, M. (2014). A primer on partial least squares structural equation modeling (PLS-SEM). Sage Publications.

Henseler, J., Ringle, C. M., \& Sarstedt, M. (2014). A new criterion for assessing discriminant validity in variance-based structural equation modeling. Journal of the Academy of Marketing Science, 43(1), 115-135. doi:10.1007/s11747-014-0403-8

Kiran, M., Prabhu, K. N., Paramesha, S. C., Rajshekar, T., Praveen, M. P., Punitkumar, C., Puneetha, S. C., Kumar, R., Rahul, Y., \& Nagabhushan, C. (2018). Consumption pattern, consumer attitude and consumer perception on meat quality and safety in Southern India. International Food Research Journal, 25(3), 1026-1030.

Kirinus, J. K., Benedetti, M., Pavlik, W., Taffarel, G. V., de Oliveira Belmonte, C., Dörr, A. C., \& Téo, A. R. (2016). Characterization of pork meat consumption of the population of Xanxerê, Santa Catarina, Brazil. Revista Eletrônica em Gestão, Educação e Tecnologia Ambiental, 20(1), 233-240.

Kratz, L. R., Moreira, B. P., Nunes, O. M., Ávila, M. R., Nascimento, S. G. S., \& Deble, L. P. (2020). Análise do consumo de carne suína no município de Dom Pedrito. Revista Desenvolvimento Socioeconômico em Debate, 6(1), 91-111.

Issanchou, S. (1996). Consumer expectations and perceptions of meat and meat product quality. Meat Science, 43, 5-19.

Malafaia, G. C., Biscola, P. H. N., \& Dias, F. R. T. (2020a). Desafios de comunicação para a cadeia produtiva da carne bovina brasileira. In CiCarne - Embrapa Gado de Corte (1-3). Infoteca-e.

Malafaia, G. C., Biscola, P. H. N., \& Dias, F. R. T. (2020b). Como será o mercado consumidor de carne bovina em 2040? In CiCarne - Embrapa Gado de Corte (1-3). Infoteca-e.

Malafaia, G. C., Biscola, P. H. N., \& Dias, F. R. T. (2020c). Projeções para o mercado de carne bovina no Brasil - 2029/2030. In CiCarne - Embrapa Gado de Corte (1-3). Infoteca-e.

Malhotra, N. K. (2011). Pesquisa de Marketing: foco na decisão. 3a ed. São Paulo: Pearson Prentice Hall.

Marin, D. (2015). Research Regarding the Purchase Decision Process of Consumer of Food Products. Scientific Papers Animal Science and Biotechnologies, 48(1), 328-332.

Martins, G. A. (2008). Estudo de Caso: uma reflexão sobre a aplicabilidade em pesquisas no Brasil. Revista de Contabilidade e Organizações, 2(2), 8-18.

Mendonça, D. J., Souza, J. A., Carvalho, E. G. C., \& Melo, F. C. (2018). Fatores que influenciam a rentabilidade das instituições financeiras bancárias brasileiras: conclusões com base na modelagem de equações estruturais. Revista de Administração, Ciências Contábeis e Sustentabilidade, 8(1), 107-123.

Mércio, T. Z., Pereira, G. R., Pereira, P. R. R. X., Zago, D., \& Barcellos, J. O. J. (2020). Comportamento do consumidor e a percepção de qualidade da carne ovina em Porto Alegre, Brasil. Pesquisa Agropecuária Gaúcha, 26(1), 101-113.

Miller, R. (2020). Drivers of consumer liking for beef, pork, and lamb: a review. Foods, 9(4), 428-454.

Nery, M. M. R., Sincorá, L. A., Brandão, M. M., \& Carneiro, T. C. J. (2020). Um Modelo Integrativo do Engajamento do Consumidor com a Marca nas Mídias Sociais. Revista Brasileira de Marketing, 19(1), 53-80.

O'Reilly, R. A., Pannier, L., Gardner, G. E., Garmyn, A. J., Luo, H., Meng, Q., Miller, M. F., \& Pethick, D. W. (2020). Influence of Demographic Factors on Sheepmeat Sensory Scores of American, Australian and Chinese Consumers. Foods, 9(4), 529-548.

Olshavsky, R. W., \& Granbois, D. H. (1979). Consumer decision making - fact or fiction? Journal of Consumer Research, 6(2), 93-100.

Ouriveis, N. F., Leite, B. F. C., Gimenes, N. K., Gomes, M. N. B., Faria, F. J. C., Souza, A. S., \& Brumatti, R. C. (2020). Factors related to the consumption of fish meat by the population of Campo Grande/MS - Brazil. Brazilian Journal of Development, 6(1), 1861-1872. 
Putra, M. S. R., \& Hartono, S. (2020). The influence of Price, Brand Image, and Time Pressure against Purchase Decision and Customer Satisfaction: case study on terminal 3 Departure's Passenger at Soekarno-Hatta International Airport. International Journal of Innovative Science and Research Technology, 5(8), 1269-1275.

Rao, T. R. (1969). Consumer's purchase decision process: stochastic models. Journal of Marketing Research, 6(3), 321-329.

Souček, M., \& Turčinkova, J. (2015). Factors for choosing a point of purchase of meat products. Acta Universitatis Agriculturae et Silviculturae Mendelianae Brunensis, 63(2), 639-646.

Souki, G. Q. (2003). Estratégias de marketing para os agentes da cadeia de carne bovina. Tese de doutorado, Programa de Pós-Graduação em Administração, Universidade Federal de Lavras, Lavras, MG, Brasil.

Steenkamp, J. B. E. (1990). Conceptual model of the quality perception process. Journal of Business Research, 21(4), 309-333.

Tabachnick, B., \& Fidell, L. 1996. Using multivariate statistics. New York: Harper Collins College Publishers.

Yin, R. K. (2001). Estudo de Caso: planejamento e métodos. 2ª Ed. Porto Alegre: Bookman.

Zhang, M., Li, L., \& Bai, J. (2020). Consumer acceptance of cultured meat in urban areas of three cities in China, Food Control, 118, 107390. 